\title{
Justiça Distributiva e Empatia em Adolescentes do Nordeste Brasileiro
}

\author{
Distributive Justice and Empathy in Adolescents from Northeastern Brazil
}

\author{
Leonardo Rodrigues Sampaio*a, Franciela de Carvalho Monte ${ }^{a}$, \\ Cleonice Pereira dos Santos Camino ${ }^{* * b} \&$ Antonio Roazzi ${ }^{c}$ \\ ${ }^{a}$ Fundação Universidade Federal do Vale do São Francisco \\ ${ }^{b}$ Universidade Federal da Paraíba \& ${ }^{c}$ Universidade Federal de Pernambuco
}

\begin{abstract}
Resumo
O objetivo principal deste trabalho foi investigar se a empatia exercia influência significativa sobre os raciocínios distributivos de 120 adolescentes, de ambos os sexos e de escolas públicas e particulares. Para tanto, utilizouse uma situação-problema na qual os respondentes tinham que decidir a maneira mais justa de distribuir dinheiro entre seis personagens que haviam trabalhado junto e que diferiam no que diz respeito à naturalidade, produtividade e necessidade. Além disto, utilizou-se o IRI de Davis para avaliar o nível de empatia dos participantes. Nos resultados, observou-se que as dimensões de tomada de perspectiva e de personal distress, além das variáveis sexo e tipo de escola exerceram influência significativa sobre as quantidades de dinheiro distribuídas entre os personagens. Estes resultados são discutidos à luz da teoria de Hoffman e de pesquisas empíricas no campo da moralidade e da justiça distributiva.

Palavras-chaves: Moralidade; justiça; distribuição; empatia.
\end{abstract}

\begin{abstract}
The main aim of this research was to investigate whether empathy influenced the distributive reasoning of adolescents. A sample of 120 teenagers, controlled by sex and type of school (public or private), took part in the investigation. Distributive justice was evaluated through a dilemma in which the participants had to decide the fairest way to share money among six workers who had worked together but were different terms of productivity, necessity and place of birth. Empathy was measured with IRI (Davis). The results show that role-taking, personal distress, sex and type of school influenced the amounts of money distributed. These results are discussed in the context of Hoffman's theory and empirical research on morality and distributive justice.

Keywords: Morality; justice; distribution; empathy.
\end{abstract}

No campo da Psicologia, os primeiros trabalhos sobre a questão da justiça distributiva, a partir de uma perspectiva, psicogenética foram feitos pelo psicólogo suíço Jean Piaget. Em seu trabalho intitulado O juízo moral na criança (1932/1994), Piaget observou que as pessoas passam por estágios de desenvolvimento moral, os quais refletem avanços no campo das dimensões cognitiva e afetiva. No que diz respeito à justiça distributiva, o psicólogo suíço observou que da infância até a adolescência os indivíduos tendem a usar diferentes princípios de distribuição, à medida que evoluem moralmente, em um curso que parte da noção de justiça distributiva por retribuição, passa pelo igualitarismo absoluto e segue em direção à justiça eqüita-

*Endereço para correspondência: Fundação Universidade Federal do Vale do São Francisco, Colegiado de Psicologia, Avenida José de Sá Maniçoba, s/n, Centro, Petrolina, PE, 56304-205. Tel.: (87) 3863 9046. E-mail: leorsampaio@yahoo.com.br

** Endereço para correspondência: Universidade Federal da Paraíba, Centro de Ciências Humanas, Letras e Artes, Departamento de Psicologia, Cidade Universitária, Campus I, João Pessoa, PB, 58090-900. Tel.: (83) 216 7006; Fax: (83) 216 7006.E-mail: cleocamino@yahoo.com.br tiva. A seqüência proposta por Piaget tem sido verificada empiricamente por estudos com crianças estadunidenses (Damon, 1977, 1980; Enright et al., 1984; McGillienddyDe Lisi, Watkins \& Vinchur, 1991; Sigelman \& Watzman, 1991) e brasileiras (Dell'Aglio \& Hutz, 2001; Sales, 2000; Sampaio, 2004), evidenciando o caráter desenvolvimentista dos julgamentos de justiça distributiva.

Outros estudos identificaram a existência de relações entre justiça distributiva e variáveis como sexo, perspectiva avaliativa e cultura dos respondentes. Dentre outras coisas, estas pesquisas demonstraram que: os homens tendem a adotar modelos distributivos que buscam recompensar o trabalho e o esforço, enquanto que as mulheres tentam assegurar o bem-estar das pessoas envolvidas na situação de distribuição, escolhendo princípios como a igualdade (Hutz, Conti \& Vargas, 1994; Leventhal \& Lane, 1970; McGillienddy-De Lisi et al, 1991); a perspectiva adotada pelos indivíduos (ator ou observador) e suas relações com as pessoas que serão beneficiadas ou prejudicadas pela distribuição influenciam significativamente as decisões de justiça distributiva (Assmar, 2000; Skarzynska, 1989); valores coletivistas estão associados a uma maior predi- 
leção pelo igualitarismo, enquanto que a prevalência de valores individualistas em países capitalistas relaciona-se à uma maior preferência pela eqüidade baseada na produtividade (Giacobbe-Miller, Miller \& Victorov, 1998; Murphy-Berman \& Berman, 2002).

Apesar da importância e validade do modelo piagetiano, este não tem sido o único referencial teórico adotado pelos pesquisadores; nem tão pouco a justiça distributiva tem sido objeto de estudo exclusivo da Psicologia. Outras matrizes teóricas amplamente utilizadas por estudiosos nas pesquisas sobre este tema originam-se dos trabalhos de Adams (1965) e Deutsch (1975).

Adams (1965) sugere que as pessoas, ao se depararem com questões ligadas à distribuição de bens, fazem uma espécie de cálculo cognitivo que avalia e compara o esforço/ envolvimento (inputs) e a quantidade de bens merecidos (outcomes) dos envolvidos nas situações de distribuição. De acordo com esta avaliação, as pessoas julgam que a eqüidade é a maneira mais justa de resolver as questões distributivas, visto que nesta se garante a retribuição adequada do esforço investido na produção dos outcomes. Note-se que esta noção de equidade é diferente daquela citada por Piaget, pois na teoria piagetiana um julgamento eqüitativo implica levar em consideração as necessidades e características pessoais dos envolvidos na situação de distribuição.

Deutsch $(1975,1989)$ contrariamente à Adams demonstra que a eqüidade não é o único princípio distributivo aplicado pelas pessoas em situações cotidianas. Na verdade, os estudos deste autor, de seus colaboradores e de outros pesquisadores (Cook \& Hegtvedt, 1983; Lamm \& Schwinger, 1980) evidenciaram a existência de múltiplos princípios distributivos, dentre os quais se destacam eqüidade, igualdade e necessidade. Além disto, Deutsch propõe que o tipo de relação interpessoal prevalente nos grupos influencia significativamente os julgamentos distributivos.

Numa ótica diferente dos autores de orientação sóciopsicológica e semelhantemente a Piaget, Hoffman (1987, 1989, 1991) julga que as relações entre afetividade e cognição têm importância fundamental para a internalização e construção dos princípios que regem a moral e a vida em sociedade. Mais especificamente, ele postula a existência de relações entre a empatia e a justiça distributiva. Ressalta-se que apesar da empatia vicária ser amplamente discutida por diversos teóricos da Psicologia (Bryant, 1987; Davis, 1983; Eisenberg \& Strayer, 1987; Rogers, 1979/2001a, 1985/2001b; Strayer, 1987; Strayer \& Eisenberg, 1987), Hoffman é o primeiro autor a propor que, a depender dos afetos empáticos gerados nas situações cotidianas e do nível de desenvolvimento cognitivoafetivo, diferentes tipos de princípios distributivos podem ser ativados e considerados os mais justos de serem aplicados naquele momento.

Considerando algumas das hipóteses levantadas por Hoffman e os resultados dos estudos empíricos citados anteriormente é que foram concebidos os principais objetivos deste estudo. Cabe mencionar ainda que a quantidade de pesquisas sobre a justiça distributiva realizada no Brasil ainda é muito pequena e que, em geral, a atenção dos pesquisadores tem se voltado, sobretudo, para o papel que os aspectos cognitivos têm sobre os julgamentos distribu-tivos, relegando a segundo plano a influência da afetividade sobre este domínio da moral. Nessa direção, esta pesquisa procurou investigar a relação entre as decisões distributivas de adolescentes e seus níveis de empatia. Além disto, buscou avaliar se variáveis sócio-demográficas como sexo, naturalidade e tipo de escola estavam relacionadas às decisões distributivas dos participantes.

\section{Método}

\section{Amostra}

A amostra foi composta por 120 estudantes do ensino médio de escolas públicas e particulares das cidades de Petrolina - PE e Juazeiro - BA, com idades variando de 13 a 18 anos $(M=16,09 ; D P=1,43)$ e dos sexos masculino e feminino ( 78 mulheres e 52 homens).

\section{Instrumentos}

Avaliação da Justiça Distributiva. Para investigar os raciocínios distributivos utilizou-se uma situação-problema na qual era solicitado aos respondentes que distribuíssem um total de $\mathrm{R} \$ 900,00$ (novecentos reais) entre seis trabalhadores que haviam cumprido uma mesma tarefa. Cada um dos trabalhadores tinha características diferentes no que diz respeito ao local de residência, nível de produtividade e aspiração quanto ao que seria feito com o dinheiro ganho na tarefa: o trabalhador $n^{\circ} 1$ residia em um bairro muito pobre de Petrolina (PE) e disse que compraria a feira da família; o trabalhador $\mathrm{n}^{\mathrm{o}} 2$ residia em um bairro qualquer da cidade de Picos (PI) e não sabia o que fazer com o dinheiro; o trabalhador $\mathrm{n}^{\mathrm{o}} 3$ morava no bairro mais rico da cidade de Juazeiro (BA) e iria usar o dinheiro para comprar um discman; o trabalhador $\mathrm{n}^{\circ} 4$ morava no bairro mais rico de Petrolina e afirmou que usaria o dinheiro para comprar um celular novo; o trabalhador $n^{\circ} 5$ residia no centro de Picos (PI) e disse que apenas juntaria o dinheiro; por fim, o trabalhador $n^{\circ} 6$ morava no bairro mais pobre da cidade de Juazeiro e também disse que iria usar o dinheiro para comprar comida para família.

Quanto à produtividade, os participantes foram informados que a empresa havia estabelecido uma meta de produção de 100 pontos, a qual foi atingida por todos, tendo os trabalhadores $n^{\circ} 3$ e $n^{\circ} 4$, diferentemente dos demais, se destacado e conseguido atingir um índice de 150 pontos. Para auxiliar na resolução da tarefa, utilizou-se um diagrama no qual apareciam as características dos trabalhadores, e miniaturas de cédulas nos valores de 10, 50 e 100 reais.

Além da própria situação-problema, utilizou-se um roteiro de entrevista semi-estruturado no qual se questionava:

1. Se aquela havia sido a maneira mais justa de distribuir o dinheiro entre os trabalhadores.

2. Por que o respondente havia distribuído o dinheiro daquela maneira. 
3. Se algum trabalhador havia sido prejudicado com a distribuição.

4. Que fatores haviam sido considerados mais importantes ou determinantes para que ele tivesse distribuído o dinheiro daquele jeito.

5. Como ele achava que deveria ser feita a distribuição de renda na sociedade.

6. Qual das opções citadas ele considerava mais justa: (a) distribuir de acordo com o quanto se produz; (b) distribuir de acordo com as necessidades das pessoas; (c) distribuir igualitariamente para todos; (d) distribuir de uma outra maneira, ou depende. Todas as perguntas foram seguidas pelos seus respectivos porquês e por questionamentos adicionais usados para esclarecer os julgamentos distributivos dos participantes.

Avaliação da Empatia. Para verificar o nível de empatia dos participantes, foi utilizada uma versão traduzida e adaptada (Ribeiro, Koller \& Camino, 2002) do Interpersonal Reactivty Index - IRI de Davis (1983), que é um instrumento do tipo lápis e papel. No IRI, a empatia é analisada como sendo um constructo composto por componentes afetivos e cognitivos, os quais são mensurados através de escalas likert com cinco níveis. Nestas escalas o respondente indica seu grau de concordância com 21 afirmativas propostas ( 1 = não me descreve bem; 5 = descreve-me muito bem), as quais avaliam três dimensões da empatia: tomada de perspectiva (TP), personal distress (PD) e consideração empática (CE). A primeira dimensão (TP) designa a capacidade cognitiva de colocar-se no lugar dos outros, assumindo seu ponto de vista. A segunda (PD) refere-se à sensação subjetiva de incômodo sentida diante de situações nas quais o indivíduo testemunha outra pessoa ser lograda ou injustiçada. Por fim, a dimensão de CE está relacionada à motivação para ajudar outros indivíduos que estejam em situação de maior necessidade ou desvantagem relativa. $\mathrm{O}$ nível geral de empatia é determinado a partir do somatório dos escores nos 21 itens do IRI, enquanto que o nível de TP, PD ou CE é calculado somando-se os escores dos sete itens destinados a mensurar cada uma das subescalas.

\section{Procedimentos}

Inicialmente foi solicitado que os respondentes distribuíssem o dinheiro entre os trabalhadores da maneira que considerassem mais justa, usando o diagrama e as miniaturas de cédulas. Para evitar efeitos de ordem, as sequiências em que os personagens eram apresentados foram randomizadas. Após a distribuição o pesquisador anotava a quantidade de dinheiro que havia sido dado a cada trabalhador e iniciava a entrevista, usando o roteiro proposto anteriormente. As respostas fornecidas pelos respondentes foram gravadas em fitas cassetes e posteriormente transcritas para análise. A etapa final da coleta de dados consistiu na aplicação do IRI, sendo que o processo ocorreu individualmente, em salas reservadas nas próprias escolas dos adolescentes e no horário normal das aulas. As análises estatísticas foram feitas com o auxilio do software estatístico SPSS 11.0.
Todos os procedimentos adotados nesta pesquisa seguiram as orientações previstas na Resolução 196/96 do Conselho Nacional de Saúde e na Resolução 016/2000 do Conselho Federal de Psicologia.

\section{Resultados}

Os testes Kruskal-Wallis e Mann-Whitney foram utilizados para verificar se as variáveis sexo, naturalidade, tipo de escola e nível de empatia influenciaram significativamente as quantidades de dinheiro distribuídas entre os personagens da história. No que diz respeito a variável sexo, o teste de Kruskall-Wallis indicou que homens e mulheres diferiram na quantidade de dinheiro dada aos trabalhadores $\mathrm{n}^{\mathrm{o}} 1(H=7,18 ;$ g.l. $=1 ; p=0,007), \mathrm{n}^{\circ} 6(H=4,78 ;$ g.l. $=1$; $p=0,029), \mathrm{n}^{\circ} 3(H=3,90 ;$ g.l. $=1 ; p=0,048)$ e $\mathrm{n}^{\circ} 4(H=$ 3,$82 ;$ g.l. $=1 ; p=0,050$ ), sendo que as mulheres deram mais dinheiro que os homens aos dois primeiros (mais necessitados), enquanto que eles deram mais dinheiro que elas para os dois últimos personagens (mais produtivos).

De acordo com as análises, a naturalidade dos respondentes não exerceu influência significativa sobre as quantidades de dinheiro distribuídas entre os trabalhadores. Neste sentido, petrolinenses e juazeirenses não diferiram nos aspectos quantitativos da distribuição. Contudo, no que diz respeito ao tipo de escola, observou-se que os estudantes de escolas públicas deram mais dinheiro ao trabalhador $\mathrm{n}^{\mathrm{o}} 1(H=8,52 ;$ g.l. $=1 ; p=0,004)$ e ao trabalhador $\mathrm{n}^{\circ} 6(H$ $=4,31 ;$ g.l. $=1 ; p=0,038)$ que os estudantes de escolas particulares. Por outro lado, os estudantes de escolas particulares deram mais dinheiro ao trabalhador $n^{\circ} 3$ do que os estudantes de escolas públicas $(H=3,66 ; g . l .=1 ; p=0,056)$.

Uma vez que a naturalidade não influenciou significativamente a distribuição de dinheiro entre os personagens, optou-se por analisar quanto havia sido dado aos mais necessitados, aos mais produtivos e aos personagens piauienses da história. Para tanto, se computou quanto foi dado aos trabalhadores $n^{\circ} 1$ e $n^{\circ} 6$, aos trabalhadores $n^{\circ} 3$ e $\mathrm{n}^{\circ} 4$ e aos trabalhadores $n^{\circ} 2$ e $n^{\circ} 5$, considerando estas quantidades como três variáveis dependentes. Observou-se que uma maior quantidade de dinheiro foi dada aos trabalhadores mais necessitados $(M=788,45 ; D P=225,57)$, que os trabalhadores de outra cidade receberam menos dinheiro $(M=476,58 ; D P=137,83)$ e que os trabalhadores mais produtivos receberam, em média, $\mathrm{R} \$ 534,95$. O teste de Friedman indicou que as diferenças entre estas médias eram estatisticamente significativas $(p<, 001)$.

Ao se verificar a influência do sexo, do tipo de escola e da naturalidade sobre estas três variáveis, observou-se que o sexo e o tipo de escola influenciaram a quantidade de dinheiro dada aos trabalhadores mais necessitados e aos mais produtivos. Neste sentido, foi constatado, conforme é ilustrado na Figura 1, que as mulheres deram mais dinheiro aos trabalhadores necessitados que os homens $(H=$ $6,702 ;$ g.l. $=1 ; p=0,01)$, e que os homens deram mais dinheiro que as mulheres aos trabalhadores mais produti$\operatorname{vos}(H=5,24 ; g . l .=1 ; p=0,022)$. Ademais, constatou-se, conforme ilustra a Figura 2, que os estudantes de escola 
pública deram mais dinheiro aos trabalhadores mais necessitados que os estudantes de escola particular $(H=6,85$; g.l. $=1 ; p=0,09)$ e que, inversamente, os estudantes de escola particular deram mais dinheiro aos personagens mais produtivos que os estudantes de escolas públicas $(H=4,04$; g.l. $=1 ; p=0,04)$.

No que diz respeito aos dados do IRI, testes de média demonstraram haver diferenças significativas entre o nível geral de empatia $(H=9,03 ; g . l .=1 ; p=0,003)$, o nível de consideração empática $(H=4,35 ;$ g.l. $=1 ; \mathrm{p}=0,037)$ e o nível de personal distress $(H=5,24 ; g . l .=1 ; p=0,022)$ obtidos por homens e mulheres. Além disto, observaram-se diferenças significativas entre estudantes de escolas particulares e de escolas públicas, quanto ao nível geral de empatia $(H=7,04 ;$ g.l. $=1 ; p=0,008)$ e ao nível de consideração empática $(H=7,35 ;$ g.l. $=1 ; p=0,007)$. A Tabela 1 apresenta as médias obtidas pelos participantes em cada uma das dimensões do IRI, segundo sexo e tipo de escola.

\section{Quantidade média de dinheiro distribuída}

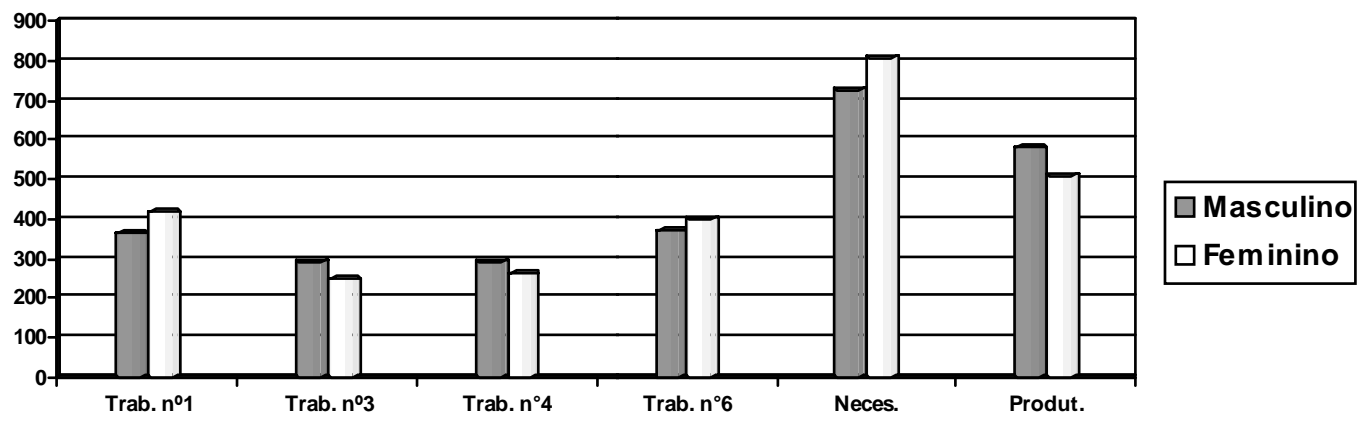

Figura 1. Quantidade de dinheiro dada aos trabalhadores $n^{\circ} 1, n^{\circ} 3, n^{\circ} 4, n^{\circ} 6$, aos mais necessitados e aos mais produtivos, de acordo com o sexo dos participantes.

Quantidade média de dinheiro distribuída

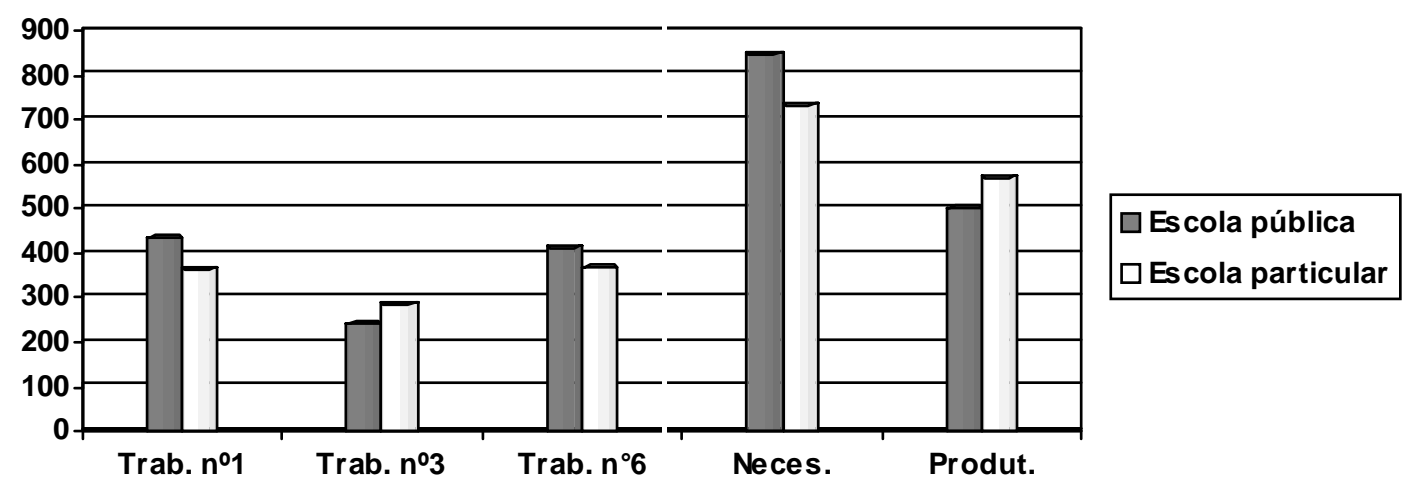

Figura 2. Quantidade de dinheiro dada aos trabalhadores $\mathrm{n}^{\circ} 1, \mathrm{n}^{\mathrm{o}} 3, \mathrm{n}^{\circ} 6$, aos mais necessitados e aos mais produtivos de acordo com o tipo de escola dos participantes.

Tabela 1

Nível Médio de Empatia Obtido pelos Participantes de Acordo com o Sexo e o Tipo de Escola no IRI e em Cada Uma de suas Subescalas

\begin{tabular}{lcccccccc}
\hline & \multicolumn{2}{c}{ Masculino } & \multicolumn{2}{c}{ Feminino } & \multicolumn{2}{c}{ Pública } & \multicolumn{2}{c}{ Particular } \\
\hline & Média & DP & Média & DP & Média & DP & Média & DP \\
\hline Nivel geral de empatia & 71,24 & 9,11 & 76,55 & 9,13 & 77,07 & 9,65 & 72,39 & 8,70 \\
Consideração empática & 26,00 & 4,46 & 27,73 & 4,18 & 28,22 & 4,35 & 26,07 & 4,09 \\
Tomada de perspectiva & 25,12 & 4,12 & 25,78 & 4,30 & 26,07 & 4,52 & 25,05 & 3,90 \\
Personal Distress & 20,12 & 4,09 & 23,04 & 4,91 & 22,78 & 5,19 & 21,28 & 4,37 \\
\hline
\end{tabular}


Considerando os valores mínimo (35) e máximo (71) alcançados pelos respondentes no IRI, o escore geral da empatia e os escores em cada uma das subescalas deste instrumento foram categorizados em três níveis: escores entre $0 \%$ e $25 \%$ da média foram considerados de nível baixo; entre $26 \%$ e $75 \%$ de nível médio; acima de $75 \%$ considerados como nível elevado.

Testes de média foram feitos para verificar se a distribuição de dinheiro variou entre os indivíduos com diferentes níveis de empatia, tomada de perspectiva, personal distress e consideração empática. O nível geral de empatia e o nível de consideração empática não exerceram influência significativa sobre as quantidades de dinheiro distribuídas para os trabalhadores. Contudo, houve variação significativa na distribuição de dinheiro de acordo com os níveis de tomada de perspectiva e personal distress. Neste sentido, os indivíduos com nível alto de personal distress deram menos dinheiro ao trabalhador $\mathrm{n}^{\circ} 4(U=7,39 ;$ g.l. $=2 ; p=0,025)$ e aos trabalhadores mais produtivos $(U=6,43$; g.l. $=2$; $p$ $=0,040$ ), do que os respondentes que obtiveram nível bai- xo e médio nesta subescala do IRI. O teste de MannWhitney demonstrou que as quantidades de dinheiro dadas pelos indivíduos com nível médio de personal distress também diferiram significativamente daquelas dadas pelos indivíduos de nível baixo nestes dois casos. Além disto, os respondentes com nível alto de personal distress deram mais dinheiro ao trabalhador $n^{\circ} 6$ do que os respondentes de nível médio ( $U=-2,20 ; p=0,027)$.

Os resultados evidenciaram ainda que os indivíduos com um nível alto de tomada de perspectiva deram mais dinheiro ao trabalhador $\mathrm{n}^{\circ} 1(U=2,11 ; p=0,035)$ e menos dinheiro ao trabalhador $n^{\circ} 3(U=-2,20 ; p=0,028)$ do que os participantes com um baixo nível de tomada de perspectiva. Ao se comparar os indivíduos de nível baixo com os de nível médio, observou-se que os primeiros deram menos dinheiro aos trabalhadores mais necessitados $(U=-$ $1,94 ; p=0,052)$ e mais dinheiro ao trabalhador $n^{\circ} 3(U=-$ $2,21 ; p=0,027)$ do que os últimos. A Tabela 2 apresenta as quantidades médias de dinheiro dadas a cada trabalhador, de acordo com o nível de tomada de perspectiva e de personal distress dos respondentes.

Tabela 2

Quantidade Média de Dinheiro dada em Cada Situação de Acordo com o Nível de Tomada de Perspectiva e de Personal Distress

\begin{tabular}{lllllll}
\hline & \multicolumn{3}{c}{ Tomada de perspectiva } & \multicolumn{3}{c}{ Personal Distress } \\
\hline & Baixo & Médio & Alto & Baixo & Médio & Alto \\
\hline Trabalhador 1 & 370,00 & 400,47 & 410,00 & 399,28 & 389,24 & 437,00 \\
Trabalhador 2 & 220,76 & 239,93 & 237,65 & 230,23 & 238,29 & 242,50 \\
Trabalhador 3 & 309,23 & 259,59 & 252,34 & 270,47 & 272,46 & 220,50 \\
Trabalhador 4 & 293,84 & 264,86 & 276,56 & 302,61 & 277,53 & 215,00 \\
Trabalhador 5 & 229,61 & 240,87 & 237,18 & 225,71 & 245,69 & 226,50 \\
Trabalhador 6 & 376,53 & 394,25 & 386,25 & 371,66 & 376,77 & 458,50 \\
Necessitados & 746,53 & 794,72 & 796,25 & 770,95 & 766,01 & 895,50 \\
Produtivos & 603,07 & 524,45 & 528,90 & 573,09 & 550,00 & 435,50 \\
Outros & 450,38 & 480,81 & 474,84 & 455,95 & 483,98 & 469,00 \\
\hline
\end{tabular}

No que se refere à análise das justificativas dadas pelos participantes, inicialmente investigou-se se as respostas refletiam os três princípios distributivos citados por Deutsch (1975). Neste sentido, foi verificado se os respondentes adotaram estratégias distributivas baseadas na igualdade, eqüidade, necessidade, ou se haviam apontado outro tipo de raciocínio alternativo, passível de resolver a distribuição de dinheiro na situação-problema. Outra parte da análise buscou verificar quais foram os princípios distributivos citados como sendo os mais justos para a distribuição de renda na sociedade.

No que diz respeito à resolução da situação-problema as justificativas foram categorizadas como sendo de necessidade quando os respondentes indicavam que o principal motivo que os teria levado a tomar aquela decisão era o fato dos trabalhadores $n^{\circ} 1$ e $n^{\circ} 6$ serem mais pobres do que os outros. Por outro lado, quando os participantes destaca- vam que a produtividade dos trabalhadores $n^{\circ} .3$ e $n^{\circ} .4$ havia sido o fator mais importante para guiar suas decisões, estas justificativas foram categorizadas como sendo eqüitativas. Por fim, as justificativas foram categorizadas como sendo igualitárias quando os indivíduos indicavam que o mais justo seria fazer uma distribuição por igual entre todos os trabalhadores.

Além destes três tipos de justificativas, observou-se que alguns respondentes consideraram, mais do que a produtividade ou a necessidade, que a finalidade para a qual o dinheiro seria destinado deveria ser o critério mais importante para guiar as distribuições. Nesta direção, alguns adolescentes consideraram que comprar alimentos para família seria um motivo nobre ou importante e que, por outro lado, comprar um celular novo ou discman seria um motivo banal, não merecedor de ganhos adicionais. No que diz respeito à frequiência de utilização destes tipos de justi- 
ficativa na resolução do dilema hipotético, observou-se que a maioria dos respondentes $(56,7 \%)$ apontou a necessidade como sendo o principal motivo que os teria levado a distribuir o dinheiro daquela maneira. A eqüidade apareceu como sendo o segundo motivo mais evocado pelos participantes $(29,8 \%)$ e, na seqüência, igualdade $(10,6 \%)$ e finalidade $(2,9 \%)$ foram, respectivamente, as justificativas mais freqüentemente utilizadas pelos respondentes.

Quanto à distribuição de renda na sociedade, observouse que os respondentes, além da necessidade, eqüidade e igualdade, utilizaram um quarto tipo de justificativa que combinava os dois primeiros tipos em um só. Neste sentido, os participantes ressaltaram que era importante haver uma atenção maior para a necessidade das pessoas mais pobres, dando-lhes algum tipo de assistência especial, mas que, além disto, dever-se-ia haver correspondência entre o trabalho/ esforço despendido e a remuneração obtida. Cerca de $42 \%$ dos adolescentes julgou que a eqüidade era o modelo de distribuição de renda mais justo a ser aplicado na sociedade, enquanto que outros $27,4 \%$ disseram que a Necessidade era um modelo mais justo. Por fim, os princípios da Equidade/ necessidade e igualdade alcançaram freqüência de $17,1 \%$ e $13,7 \%$ de utilização, respectivamente.

\section{Discussão e Considerações Finais}

A análise dos dados demonstrou que o nível geral de empatia não exerceu influência significativa sobre as decisões distributivas dos respondentes. Todavia, outros resultados indicaram que componentes cognitivos e afetivos deste constructo podiam estar relacionados à maneira como as pessoas julgaram a justiça distributiva. No que diz respeito especificamente à cognição, a tomada de perspectiva pareceu ter desempenhado papel-chave nas decisões dos participantes.

Ao contrário do que algumas pessoas podem imaginar, uma maior capacidade de colocar-se no lugar do outro não implica, necessariamente, que o indivíduo irá tomar decisões parciais que favoreçam a uns, e não a outros. Por outro lado, considera-se que níveis mais elevados nesta dimensão refletem uma maior capacidade de assumir o ponto de vista de todos os envolvidos na situação, de considerar as razões de cada pessoa e de ponderar os direitos individuais pertinentes à vida em sociedade. Corroborando este ponto de vista, verifica-se que a avaliação sobre a justiça distributiva dos participantes desta pesquisa foi baseada em um julgamento no qual a necessidade de alguns personagens figurou como um critério importante, mas que não desmerecia o esforço e a eficiência de outros personagens.

Assim, a decisão distributiva mais justa pode ter sido vista por alguns como aquela que favoreceria um pouco os mais necessitados, mas que também não prejudicaria aqueles que produziam mais, como foi o caso dos respondentes com nível médio e alto de tomada de perspectiva. Já os respondentes com nível baixo de tomada de perspectiva podem ter dado mais dinheiro aos personagens mais produtivos porque seus julgamentos distributivos focalizaram, sobretudo, a questão do merecimento por produção, sem conseguir coordenar as características e condições pessoais dos outros trabalhadores.

Outro fato a ser mencionado refere-se à influência exercida pela dimensão de personal distress sobre as quantidades de dinheiro distribuídas entre os personagens. Observouse que quanto maior o nível de personal distress maior era a tendência de favorecer os trabalhadores mais necessitados. Considera-se que a sensação subjetiva de incômodo ou desconforto provocada pelo destaque da necessidade dos trabalhadores $n^{\circ} 1$ e $n^{\circ} 6$ mobilizou afetivamente os participantes a buscar aliviar este sentimento, ajudando àqueles personagens.

Também se pode inferir que o comportamento dos participantes pode ter sido influenciado pela desejabilidade social mobilizada em uma situação de pesquisa como esta. Estudos anteriores sobre a empatia (Bryant, 1987; Strayer, 1987; Strayer \& Eisenberg, 1987) indicaram que a utilização de instrumentos como o IRI está sujeita a este tipo de influência, visto que os respondentes podem se avaliar como sendo mais empáticos do que realmente o são. Assim, é possível que, para evitar o aumento da angústia pessoal no self os participantes tenham optado por favorecer os personagens mais necessitados, para poderem ser vistos como pessoas altruístas, benévolas, caridosas e assim por diante.

Os resultados desta pesquisa corroboram estudos anteriores nos quais se observaram diferenças nos julgamentos distributivos relacionadas ao sexo, pois se constatou que as mulheres favoreceram os personagens mais necessitados e os homens os mais produtivos. Considera-se que estes resultados indicam que a noção de justiça distributiva esteja associada aos papéis atribuídos a homens e mulheres em nossa sociedade. Neste sentido, julga-se a possibilidade de que para as mulheres essa concepção de justiça esteja vinculada a uma preocupação em proteger e suprir as necessidades de pessoas mais necessitadas, mais do que em recompensar ou punir alguém por conta do seu desempenho. Por outro lado, os homens podem ter se comportado de acordo com um padrão de justiça no qual se privilegia o esforço e a produtividade das pessoas, haja visto que eles são vistos, pela maioria das pessoas, como principais figuras provedoras do sustento financeiro da instituição familiar.

No que diz respeito às diferenças nos níveis de empatia em função do sexo, os resultados desta pesquisa corroboram estudos anteriores (Bryant,1987; Strayer, 1987; Strayer \& Eisenberg, 1987) nos quais se observou que as mulheres atingem escores mais elevados que os homens nas medidas de empatia. A utilização de um instrumento como o IRI, bem como o próprio processo de socialização, podem estar relacionados a essas diferenças no sentido de que as mulheres podem ter pretendido demonstrar ser mais afetuosas, caridosas e cuidadosas, enquanto que os homens a querer aparentar maior objetividade, seriedade e racionalidade, em função dos diferentes papéis que ambos assumem na sociedade.

Quanto à influência do tipo de escola sobre as distribuições, considera-se que as mesmas também podem ter sido provocadas pelos afetos empáticos mobilizados durante a resolução do dilema hipotético. Como Hoffman (1987, 
1991) ressalta a empatia não é livre de vieses; pelo contrário, a depender do nível de desenvolvimento cognitivoafetivo do indivíduo e das pistas situacionais presentes, os julgamentos e comportamentos morais podem ser altamente influenciados pelos afetos empáticos. Nesta direção, sugere-se que as informações fornecidas no dilema hipotético acerca das aspirações e dos locais de moradia dos personagens fizeram com que os sujeitos da pesquisa construíssem representações cognitivo-afetivas sobre os seis trabalhadores. Estas representações podem ter mobilizado sentimentos de identificação nos respondentes, os quais fizeram com que eles favorecessem os personagens considerados mais semelhantes - em termos de situação sócio-econômica - a eles mesmos, caracterizando uma espécie de parcialidade nos julgamentos morais, chamada de viés da proximidade (Hoffman, 1989). Nesse caso, é provável que os estudantes de escola pública tenham tomado suas decisões a partir do princípio da necessidade, pois este é o que mais beneficia pessoas pobres e necessitadas, assim como a maioria deles. Por outro lado, os estudantes de escola particular podem ter destacado a questão da produtividade dos personagens, porque esse critério beneficia pessoas com nível sócio-econômico mais elevado, que já estejam inseridas no mercado de trabalho e que tenham suas necessidades básicas já supridas. Essa hipótese a respeito da familiaridade pode ajudar a explicar também o porquê dos personagens da cidade de Picos (PI) terem recebido menos dinheiro que os outros. Como Petrolina e Juazeiro são duas cidades vizinhas e que compartilham muitas características sócio-culturais, é provável que os participantes tenham considerado os trabalhadores de Picos mais diferentes ou distantes do que os outros personagens.

Outras análises indicam que os adolescentes utilizaram justificativas baseadas na equiidade, igualdade e necessidade. A necessidade foi mais utilizada durante a resolução da situação-problema, enquanto que a eqüidade foi considerada o princípio mais justo de distribuição de renda na sociedade. Ressalta-se que a eqüidade indicada pelos respondentes assemelha-se à noção defendida por Piaget (1932/1994), pois os respondentes alegaram ser justo recompensar as pessoas mais trabalhadoras e esforçadas, mas que, por outro lado, faz-se necessário também que o governo torne a distribuição de renda mais equilibrada, criando mecanismos para ajudar indivíduos em condições de maior necessidade. Assim, constatou-se que para os participantes a noção de justiça aplicada à distribuição de renda na sociedade passa pela consideração de diferentes fatores, dentre os quais estão o esforço, produtividade e as demandas ou necessidades das pessoas.

Acredita-se que a distribuição baseada na necessidade foi considerada a mais justa na situação-problema porque esta apresentava pistas situacionais mais evidentes, as quais foram utilizadas pelos respondentes durante suas tomadas de decisão. Estas pistas podem ter mobilizado os afetos empáticos dos sujeitos, fazendo com que eles optassem, mais freqüentemente, pelo princípio da necessidade, buscando favorecer os personagens mais pobres. Por outro lado, é possível que ao avaliar o modelo distributivo mais justo a ser aplicado na sociedade as pistas situacionais tenham sido mais fracas, visto que não era possível elaborar representações mentais sobre pessoas específicas, o que fez com que sentimentos empáticos não tenham sido tão prontamente mobilizados. Assim, o julgamento sobre a distribuição de renda na sociedade pode ter sido mais livre de vieses afetivos, o que fez com que os respondentes aderissem mais ao princípio da eqüidade, o qual é considerado justo em uma sociedade capitalista e altamente competitiva como a nossa.

É importante destacar ainda a presença de justificativas baseadas na finalidade (aplicação do dinheiro) e na articulação entre eqüidade e necessidade. Considera-se que a opção por estes tipos de justificativas pode estar relacionada aos níveis de desenvolvimento cognitivo e afetivo dos respondentes, pois julgamentos baseados na finalidade parecem refletir uma concepção de justiça mais estreita, ligada aos aspectos práticos e objetivos da situação. Por outro lado, uma justificativa que tenta articular necessidade e eqüidade pode refletir uma capacidade elevada de tomada de perspectiva, pois através dessa o indivíduo é capaz de assumir e coordenar diferentes pontos de vista. Estudos posteriores podem investigar se esta hipótese é plausível, analisando a utilização destes tipos de justificativa e sua relação com aspectos do desenvolvimento cognitivo-afetivo.

Apesar da análise dos dados sugerir que afetos empáticos exercem influência sobre os julgamentos distributivos, isto não quer dizer que a empatia deve ser considerada o único e nem o mais importante fator nas decisões distributivas. É importante lembrar que o desenvolvimento sócio-moral é um processo que sofre influência de fatores diversos em nível micro (aspectos cognitivo-afetivos) e macro (ambiente sócio-cultural) e que a explicação psicológica mais adequada para os julgamentos e comportamentos da vida em sociedade deve levar em consideração estas influências múltiplas. Nessa direção, esta pesquisa configura-se como uma tentativa inicial de investigar se fatores afetivos estão relacionados à moralidade e, mais especificamente, à questão da justiça distributiva.

Ressalta-se que alguns dos resultados deste estudo podem ter sido influenciados pela distribuição amostral e pelo próprio design da pesquisa. Sugere-se que pesquisas posteriores, aprofundem a investigação a respeito dos efeitos das pistas situacionais sobre as decisões distributivas, evitando mencionar qual será o destino do dinheiro distribuído e manipulando diferentes níveis de necessidade e produtividade. Além disto, é importante que pesquisas subseqüentes garantam uma estratificação mais adequada em função do sexo, visto que os resultados deste e de estudos anteriores demonstram que esta variável pode estar fortemente associada a diferenças nos julgamentos de justiça distributiva.

\section{Referências}

Adams, J. S. (1965). Inequity in social exchange. In L. Berkowitz (Ed.), Advances in experimental social psychology (pp. 267299). New York: Academic Press. 
Assmar, E. M. L. (2000). A psicologia social e o estudo da justiça em diferentes níveis de análise. Psicologia: Reflexão $e$ Crítica, 13(3), 497-506.

Bryant, B. K. (1987). Critique of comparable questionnaire methods in use to access empathy in children and adults. In N. Eisenberg \& J. Strayer (Eds.), Empathy and its development (pp. 361-373). New York: Cambridge University Press.

Cook, K. S., \& Hegtvedt, K. A. (1983). Distributive justice, equity, and equality. Annual Review of Sociology, 9, 217-241.

Damon, W. (1977). The social word of the child. San Francisco, CA: Jossey-Bass.

Damon, W. (1980). Patterns of change in children's social reasoning: A two-year longitudinal study. Child Development, $51,1010-1017$.

Davis, M. H. (1983). Measuring individual differences in empathy: Evidence for a multidimensional approach. Journal of Personality and Social Psychology, 44, 113-136.

Deutsch, M. (1975). Equity, equality, and need: What determines which value will be used as the basis of distributive justice. Journal of Social Issues, 31(3), 137- 149.

Deutsch, M. (1989). Equality and economic efficiency: Is there a trade-off? In N. Eisenberg, J. Roykowsky \& E. Staub (Eds.), Social and moral values: Individual and societal perspectives (pp. 139-152). Hillsdale, NJ: Larry Erlbaum Associates.

Dell'Aglio, D. D., \& Hutz, C. S. (2001). Padrões evolutivos na utilização dos princípios de justiça distributiva em crianças e adolescentes no sul do Brasil. Psicologia: Reflexão e Crítica, 24(1), 97-106.

Eisenberg, N., \& Strayer, J. (1987). Empathy and its development. New York: Cambridge University Press.

Enright, R. D., Bjerstedt, A., Enright, W. F., Levy, V. M., Jr., Lapsley, D. K., Buss, R. B., Harwell, M., \& Zindler, M. (1984). Distributive justice development: Cross-cultural, contextual and longitudinal evaluations. Child Development, 55, 17371751.

Giacobbe-Miller, J., K., Miller, D. J., \& Victorov, V. I. (1998). A comparison of Russian and U.S. pay allocation decision, distributive justice judgments and productivity under different payment conditions. Personnel Psychology, 1(27), 137-154.

Hoffman, M. L. (1987). The contribution of empathy to justice and moral judgment. In N. Eisenberg \& J. Strayer (Eds.), Empathy and its development (pp. 47-79). New York: Cambridge University Press.

Hoffman, M. L. (1989). Empathy, role-taking, guilt and development of altruistic motives. In N. Eisenberg, J. Roykowsky \& E. Staub (Eds.), Social and Moral Values: Individual and societal perspectives (pp. 139-152). Hillsdale, NJ: Larry Erlbaum Associates.

Hoffman, M. L. (1991). Empathy, social cognition and moral action. In W. M. Kurtines \& J. L. Gewirtz (Eds.), Handbook of moral behavior and development: Vol. 1 (pp. 271-305). Hillsdale, NJ: LEA.

Hutz, C. S., Conti, L., \& Vargas, S. (1994). Rules used by Brazilian students in systematic and nonsystematic reward allocation. Journal of Social Psychology, 134(3), 331-338.

Lamm, H., \& Schwinger, T. (1980). Norms concerning distributive justice: Are needs taken into consideration in allocation decisions? Social Psychology Quarterly, 43(4), 425-429.

Leventhal, G. S., \& Lane, D. W. (1970). Sex, age, and equity behavior. Journal of Personality and Social Psychology, 15 (4), 312-316.

Mcgillienddy-De Lisi, A. V., Watkins, C., \& Vinchur, A. J. (1991). The effect of relationship on children's distributive justice reasoning. Child Development, 65, 1694-1700.
Murphy-Berman, V., \& Berman, J. (2002). Cross-cultural differences in perceptions of distributive justice: A comparison of Hong Kong and Indonesia. Journal of Cross-Cultural Psychology, 33(2), 157-170.

Piaget, J. (1994). O juízo moral na criança (2. ed.). São Paulo, SP: Summus. (Original publicado em 1932)

Ribeiro, J., Koller, S. H., \& Camino, C. (2002). Adaptação e validação de duas escalas de empatia para uso no Brasil. Estudos de Psicologia (Campinas), 18(3), 43-53.

Rogers, C. R. (2001a). Sobre o poder pessoal (4. ed.). São Paulo, SP: Martins Fontes (Original publicado em 1979)

Rogers, C. R. (2001b). Tornar-se pessoa (5. ed.). São Paulo, SP: Martins Fontes (Original publicado em 1985)

Sales, E. M. B. (2000). O conceito de justiça distributiva relacionado às normas sociais escolares. Psicologia Reflexão e Crítica, 13(1), 49-58.

Sampaio, L. R. (2004). O desenvolvimento da justiça distributiva em crianças. Dissertação de Mestrado não-publicada, Programa de Pós-Graduação em Psicologia Cognitiva, Universidade Federal de Pernambuco, Recife, PE.

Sigelman, C. K., \& Waitzman, K. A. (1991). The development of distributive justice orientations: Contextual influences on children's resource allocations. Child Development, 62, 13671378.

Skarzynska, K. (1989). Evaluative perspective and distributive justice. In N. Eisenberg, J. Roykowsky \& E. Staub (Eds.), Social and moral values: Individual and societal perspectives (pp. 139-152). Hillsdale, NJ: Lawrence Erlbaum.

Strayer, J. (1987). Picture-story indices of empathy. In N. Eisenberg \& J. Strayer (Ed.), Empathy and its development (pp. 351-355). New York: Cambridge University Press.

Strayer, J., \& Eisenberg, N. (1987). Empathy viewed in context. In N. Eisenberg \& J. Strayer (Eds.), Empathy and its development (pp. 389-398). New York: Cambridge University Press. 